\title{
Isomerization and Fragmentation of Methylfuran Ions and Pyran Ions in the Gas Phase $\dagger$
}

Rüdiger Spilker and H.-F. Grützmacher $\ddagger$

Fakultät für Chemie, Universität Bielefeld, Universitätsstraße 25, D-4800 Bielefeld 1, FRG

\begin{abstract}
The mutual interconversion of the molecular ions $\left[\mathrm{C}_{5} \mathrm{H}_{6} \mathrm{O}\right]^{+*}$ of 2-methylfuran (1), 3-methylfuran (2) and $4 \mathrm{H}$-pyran (3) before fragmentation to $\left[\mathrm{C}_{5} \mathrm{H}_{5} \mathrm{O}\right]^{+}$ions has been studied by collisional activation spectrometry, by deuterium labelling, by the kinetic energy release during the fragmentation, by appearance energies and by a MNDO calculation of the minimum energy reaction path. The electron impact and collisional activation mass spectra show clearly that the molecular ions of 1-3 do not equilibrate prior to fragmentation, but that mostly pyrylium ions $\left[\mathrm{C}_{5} \mathrm{H}_{5} \mathrm{O}\right]^{+}$arise by the loss of a $\mathrm{H}$ atom. This implies an irreversible isomerization of methylfuran ions 1 and 2 into pyran ions before fragmentation, in contrast to the isomerization of the related systems toluene ions/cycloheptatriene ions. Complete $\mathbf{H} / \mathrm{D}$ scrambling is observed in deuterated methylfuran ions prior to the $H / D$ loss that is associated with an iostope effect $k_{H} / k_{D}=1.67-2.16$ for metastable ions. In contrast, no $\mathrm{H} / \mathrm{D}$ scrambling has been observed in deuterated $4 \mathrm{H}$-pyran ions. However, the loss of a $\mathrm{H}$ atom from all metastable $\left[\mathrm{C}_{5} \mathrm{H}_{6} \mathrm{O}\right]^{+*}$ ions gives rise to a flat-topped peak in the mass-analysed ion kinetic energy spectrum and a kinetic energy release $\left(T_{50}\right)$ of $26 \pm 1.5 \mathrm{~kJ} \mathrm{~mol}^{-1}$. The MNDO calculation of the minimum energy reaction path reveals that methylfuran ions $1^{+\cdot}$ and $2^{+\cdot}$ favour a rearrangement into pyran ions before fragmentation into furfuryl ions, but that the energy barrier of the first rearrangement step is at least of the same height as the barrier for the dissociation of pyran ions into pyrylium ions. This agrees with the experimental results.
\end{abstract}

\section{INTRODUCTION}

The mutual interconversion of toluene molecular ions and cycloheptatriene molecular ions is probably the best known example of a skeletal rearrangement of an organic ion. ${ }^{1}$ It has been firmly established by a variety of mass spectrometric and related techniques that a complete equilibrium is reached for those $\left[\mathrm{C}_{7} \mathrm{H}_{8}\right]^{+\cdot}$ ions with sufficient internal energy for the loss of a hydrogen atom, ${ }^{2}$ and the reaction energy profile for the isomerization and fragmentation has been studied by MNDO calculations. ${ }^{3}$ A similar study has been made for the isomerization and fragmentation of xylene molecular ions and related $\left[\mathrm{C}_{8} \mathrm{H}_{10}\right]^{+\cdot}$ ions. ${ }^{4}$ For $\left[\mathrm{C}_{7} \mathrm{H}_{8}\right]^{+\cdot}$ and $\left[\mathrm{C}_{8} \mathrm{H}_{10}\right]^{+\cdot}$ the energy barriers for the interconversion of isomeric ions are below the threshold energy for the fragmentation. Hence, fragmentation is the reaction step determining the activation energy of the total process and Gaussianshaped peaks are observed for the loss of $\mathrm{H}^{*}$ and of $\dot{\mathrm{C}} \mathrm{H}_{3}$, respectively, from $\left[\mathrm{C}_{7} \mathrm{H}_{8}\right]^{+\cdot}$ and $\left[\mathrm{C}_{8} \mathrm{H}_{10}\right]^{+\cdot} .4 \mathrm{a}, 5$

Much less is known about the isomerization and fragmentation of the molecular ions of alkylated heteroaromatics, ${ }^{6}$ but usually it is postulated that these ions behave in close analogy to alkylated

$\dagger$ Dedicated to Prof. Dr T. Gäumann on the occasion of his 60 th birthday.

$\ddagger$ Author to whom correspondence should be addressed. benzene ions. The $70-\mathrm{eV}$ mass spectra of $n$ alkylfurans ${ }^{6 \mathrm{~b}}$ exhibit a large peak of $\left[\mathrm{C}_{5} \mathrm{H}_{5} \mathrm{O}\right]^{+}$ions at $m / z 81$, which arise formally by a 'benzylic' cleavage from the molecular ions and which may correspond either to furfuryl ions $a$ or pyrylium ions $b$ (Scheme 1 ); in the latter case, the pyrylium ions $b$ may arise by a rearrangement in the molecular ion or subsequent to the fragmentation. This gives the network of isomerization and fragmentation reactions shown in Scheme 1.

However, although the $70-\mathrm{eV}$ electron impact (EI) mass spectra of 2-methylfuran (1) and 3-methylfuran (2) are very similar they are not identical, but that of 1 contains a unique peak of $\left[\mathrm{CH}_{3} \mathrm{CO}\right]^{+}$ions, $\mathrm{m} / z \mathbf{z} 4{ }^{6}$ Furthermore, we have shown recently that the molecular ions of isomeric dimethylfurans can be distinguished by their collisional activation (CA)

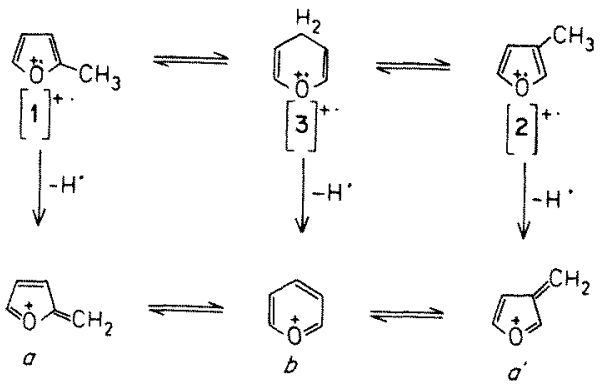

Scheme 1. Possible reaction scheme of $\left[\mathrm{C}_{5} \mathrm{H}_{6} \mathrm{O}\right]^{+*}$ ions. 
spectra. ${ }^{7}$ These observations demonstrate clearly that the molecular ions of isomeric alkylfurans do not isomerize completely by ring expansion to the corresponding pyran ions prior to fragmentations, in contrast to the behaviour of toluene ions and xylene ions. In contrast, Audier et al. ${ }^{8}$ have observed that furfuryl ions $a$, do not isomerize into pyrylium ions $b$, if the ions $a$ are formed by chemical ionization (CI). Thus, the reaction energy profiles for the reactions shown in Scheme 1 have to be clearly different from those for the analoguous reactions of alkylbenzene ions and benzyl and tropylium ions, respectively. In this paper, we report the results of a study of the isomerizations and fragmentations of molecular ions of 2-methylfuran (1), 3-methylfuran (2), 4H-pyran (3) and pentadienal (4), which shed some light on the reactions of $\left[\mathrm{C}_{5} \mathrm{H}_{6} \mathrm{O}\right]^{+*}$ ions.
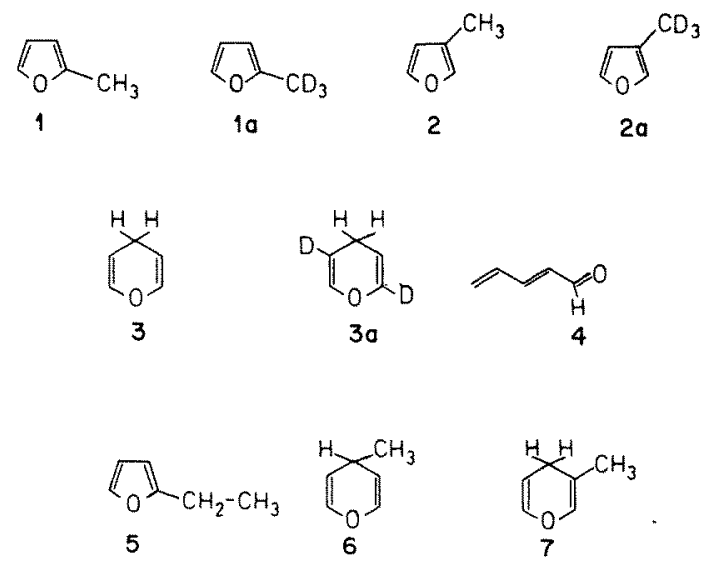

\section{RESULTS}

\section{Collisional activation mass spectra of $\left[\mathrm{C}_{5} \mathrm{H}_{6} \mathrm{O}\right]^{+*}$ and} $\left[\mathrm{C}_{5} \mathrm{H}_{5} \mathrm{O}\right]^{+}$

The CA mass spectra of the isomeric $\left[\mathrm{C}_{5} \mathrm{H}_{6} \mathrm{O}\right]^{+*}$ molecular ions of 1-4 are given in Table 1. The CA spectrum of the 2-methylfuran ions $1^{+*}$ differs from those of the isomers by a distinct peak at $m / z 43$, as observed for the EI mass spectra of these compounds. ${ }^{6}$ The CA spectrum of the pentadienal ions $[4]^{+\cdot}$ shows additional small peaks at $m / z 63$ and $m / z 62$, and the peak at $m / z 55$ is missing. Otherwise, the CA spectra of $[1]^{+\cdot}-[4]^{+\cdot}$ are rather similar and show only intensity variations for the main products of the decompositions at $m / z 53-51, m / z 39$ and $m / z 27$. Nevertheless, as the $m / z 43$ fragment ions typical of the 2-methylfuran structure are not observed in the CA spectra of $[2]^{+-}-[4]^{+*}$, a free interconversion between isomeric ions $[1]^{+\cdot}-[4]^{+\cdot}$ giving rise to an equilibrium mixture can be excluded for those $\left[\mathrm{C}_{5} \mathrm{H}_{6} \mathrm{O}\right]^{+-}$ions $(\mathrm{m} / z 82)$ reaching the second field-free region (2nd FFR) of a $V G Z A B-2 F$ mass spectrometer. This is corroborated by the $\mathrm{CA}$ spectra (Table 1) of $\left[\mathrm{C}_{6} \mathrm{H}_{8} \mathrm{O}\right]^{+\cdot}$ ions of 2-ethylfuran (5), 4-methyl-4H-pyran (6) and 3-methyl-4H-pyran (7), which are homologues of 1-4. In this case, the CA
Table 1. CA spectra of the molecular ions of 1-7 (70-eV EI, He collision gas)

$\begin{array}{rrrrrrrr}m / 2 & 1 & 2 & 3 & 4 & 5 & 6 & 7 \\ 95 & - & - & - & - & (219) & (32) & (295) \\ 81 & (165) & (159) & (537) & (200) & (137) & (414) & (22) \\ 80 & & & & & & 3 & 1 \\ 79 & & & & & & 1 & \\ 68 & & & & & (1) & (3) & (9) \\ 67 & & & & & 5 & 5 & 10 \\ 66 & & & & & 4 & 3 & 5 \\ 65 & & & & & 6 & 5 & 7 \\ 64 & & & & & 2 & 1 & 1 \\ 63 & & & & 1 & 2 & 2 & 2 \\ 62 & & & & <1 & 1 & 1 & 1 \\ 57 & & & & & 2 & & \\ 55 & 1 & 1 & 4 & & 1 & 1 & 2 \\ 54 & (15) & (16) & (10) & (30) & 1 & 2 & 1 \\ 53 & 27 & 25 & 17 & 22 & 10 & 8 & 6 \\ 52 & 8 & 7 & 8 & 6 & 4 & 5 & 3 \\ 51 & 9 & 11 & 11 & 10 & 5 & 7 & 4 \\ 50 & 7 & 8 & 8 & 7 & 4 & 6 & 3 \\ 49 & 2 & 3 & 4 & 3 & 2 & 3 & 1 \\ 43 & 7 & & & & & & 1 \\ 42 & 1 & & & & & 12 \\ 41 & & & & & & & \\ 40 & & & 1 & 1 & 3 & 4 & 6 \\ 39 & 10 & 10 & 9 & 14 & 12 & 11 & 14 \\ 38 & 4 & 5 & 4 & 4 & 5 & 4 & 4 \\ 37 & 3 & 3 & 2 & 2 & 3 & 2 & 2 \\ 29 & 2 & 4 & 4 & 4 & 4 & 2 & 1 \\ 28 & 2 & 2 & 4 & 3 & 1 & 1 & 1 \\ 27 & 10 & 12 & 15 & 16 & 5 & 5 & 4 \\ 26 & 2 & 3 & 6 & 4 & 2 & 2 & 1\end{array}$

a In \% of total fragment ions. Values in parentheses correspond to signals also observed in the MIKE spectra and are not included in the normalization.

spectra of the $\left[\mathrm{C}_{6} \mathrm{H}_{8} \mathrm{O}\right]^{+*}$ ions $(\mathrm{m} / z 96)$ are clearly different even for the positional isomers 6 and 7 . The same result has been obtained for the CA spectra of $\left[\mathrm{C}_{6} \mathrm{H}_{8} \mathrm{O}\right]^{+\cdot}$ ions from isomeric dimethylfurans. ${ }^{7}$ Note that again only the CA spectrum of 5 contains a peak at $m / z 57$, which very likely corresponds to $\left[\mathrm{C}_{2} \mathrm{H}_{5} \mathrm{CO}\right]^{+}$ions and which indicates that at least some of the molecular ions of 5 retain the structure of 2-ethylfuran.

The formation of $\left[\mathrm{C}_{5} \mathrm{H}_{5} \mathrm{O}\right]^{+}$ions $(\mathrm{m} / z \mathrm{81})$ by loss of $\mathrm{H}^{*}$ is the main reaction in the $70-\mathrm{eV}$ mass spectra of 1-4 and is by far the most intense fragmentation of metastable ions $[1]^{+\cdot}-[4]^{+*}($ Table 2$)$. The $\left[\mathrm{C}_{5} \mathrm{H}_{5} \mathrm{O}\right]^{+}$

Table 2. MIKE spectra of the molecular ions of 1-7 (70-eV EI) and kinetic energy releases, $T_{50}$

\begin{tabular}{crrrrrr}
\multicolumn{3}{c}{ MIKE spectrum } & \multicolumn{3}{c}{$T_{50}\left(\mathrm{~kJ} \mathrm{~mol} \mathrm{mo}^{-1}\right)$} \\
$\mathrm{m} / \mathrm{z}$ & 95 & 81 & 68 & 54 & 95 & 81 \\
1 & - & 98.7 & - & 1.3 & - & 24.6 \\
2 & - & 96.3 & - & 3.7 & - & 27.6 \\
3 & - & 96.1 & - & 3.9 & - & 26.4 \\
4 & - & 94.6 & - & 5.4 & - & 25.3 \\
$\mathbf{5}$ & 10.1 & 89.2 & 0.7 & - & 27.2 & 4.6 \\
6 & 6.1 & 91.5 & 2.4 & - & - & 0.5 \\
7 & 97.2 & 1.4 & 1.4 & - & 22.6 & 4.8 \\
\hline
\end{tabular}


Table 3. CA spectra of $\left[\mathrm{C}_{5} \mathrm{H}_{5} \mathrm{O}\right]^{+}$ions, $m / z 81^{\mathrm{a}}$ (70-eV EI, He collision gas)

$\begin{array}{rrrrrrrr}m / z & 1 & 2 & 3 & 4 & 5 & 6 & 7 \\ 53 & (44) & (46) & (25) & (28) & (35) & (31) & (32) \\ 52 & 14 & 13 & 9 & 9 & 10 & 13 & 13 \\ 51 & 21 & 21 & 18 & 17 & 18 & 22 & 21 \\ 50 & 17 & 16 & 15 & 16 & 16 & 17 & 17 \\ 49 & 7 & 7 & 7 & 7 & 6 & 7 & 6 \\ 48 & 2 & 2 & 2 & 2 & 2 & 1 & 1 \\ 42 & 2 & & & & 2 & & \\ 39 & 3 & 4 & 4 & 5 & 5 & 3 & 3 \\ 38 & 3 & 4 & 5 & 5 & 5 & 4 & 4 \\ 37 & 3 & 3 & 5 & 4 & 4 & 3 & 4 \\ 36 & 1 & 1 & 1 & 2 & 2 & 1 & 1 \\ 29 & 4 & 5 & 6 & 5 & 5 & 6 & 5 \\ 27 & 14 & 15 & 17 & 17 & 17 & 14 & 14 \\ 26 & 4 & 5 & 7 & 8 & 5 & 6 & 6 \\ 25 & 1 & 1 & 1 & 2 & 1 & 1 & 2\end{array}$

${ }^{a}$ In $\%$ of total fragment ions. Values in parentheses correspond to signals also observed in the MIKE spectra and are not included in the normalization.

ions $\left(\mathrm{m} / z\right.$ 81) are also formed by loss of $\mathrm{CH}_{3}{ }^{\cdot}$ from unstable and metastable ions $[5]^{+\cdot}-[7]^{+\cdot}$. The CA spectra of these $\left[\mathrm{C}_{5} \mathrm{H}_{5} \mathrm{O}\right]^{+}$ions are shown in Table 3 . With the exception of the $m / z 81$ ions derived from 1 and 5, the CA spectra are identical within the limits of error and differ only slightly by variations in the relative intensities of the peaks. Thus, $\left[\mathrm{C}_{5} \mathrm{H}_{5} \mathrm{O}\right]^{+}$ions of the same structure or the same mixture of structures are formed from these precursors. The CA spectra of $\mathrm{m} / z 81$ ions from 1 and 5 contain a small but distinctly larger peak at $m / z 42$, which can be attributed to the presence of an additional ion structure.

\section{Deuterated compounds}

The reactions of the molecular ions of methylfurans and methylpyrans have been further studied by the aid of the deuterated derivatives 2-trideuteromethylfuran (1a), 3-trideuteromethylfuran (2a) and 2,5-dideutero$4 H$-pyran (3a). The relative abundances of the losses of $\mathrm{H}^{*}$ and $\mathrm{D}^{\cdot}$, respectively, from metastable molecular ions and after collisional activation in the 2nd FFR are given in Table 4. The formation of furfuryl ions $a$ (Scheme 1) by a direct bond cleavage within the methyl group of $[1]^{+\cdot}$ and $[2]^{+\cdot}$ would correspond to specific loss of $D^{-}$in the case of $[\mathbf{1 a}]^{+\cdot}$ and $[2 a]^{+\cdot}$. In contrast to this expectation, the metastable molecular ions of $1 \mathrm{a}$ and $2 \mathrm{a}$ prefer loss of $\mathrm{H}^{\circ}$ by 62.5 and $68.3 \%$,

Table 4. Relative loss of $H^{\circ}$ and $D^{\circ}$ from molecular ions of $1 \mathrm{a}, \mathbf{2 a}$ and $3 a$

\begin{tabular}{ccccc} 
& \multicolumn{2}{c}{ MIKE spectrum } & \multicolumn{2}{c}{ CA spectrum } \\
& $(M-H)$ & $(M-D)$ & $(M-H)$ & $(M-D)$ \\
$1 a$ & 62.5 & 37.5 & 50.1 & 49.9 \\
$2 a$ & 68.3 & 31.7 & 50.1 & 49.9 \\
$3 a$ & 90.9 & 9.1 & 90.7 & 9.3 \\
\hline
\end{tabular}

respectively. This would correspond formally to a preferred cleavage of a $\mathrm{C}-\mathrm{H}$ bond at the heteroaromatic nucleus, which is very unlikely because of its large dissociation energy. Indeed, collisional activation of $[\mathbf{1} \mathbf{a}]^{+\cdot}$ and $[\mathbf{2 a}]^{+\cdot}$ prior to decomposition results in both cases in a 1:1 ratio for the loss of $\mathrm{H}^{*}$ and $\mathrm{D}^{*}$, corresponding to a statistical loss of $\mathrm{H}^{*}$ or $\mathrm{D}^{\cdot}$ from these $\left[\mathrm{C}_{5} \mathrm{H}_{3} \mathrm{D}_{3} \mathrm{O}\right]^{+\cdot}$ ions (Table 4). This shows that complete randomization of $\mathrm{H}^{\circ}$ and $\mathrm{D}^{*}$ has occurred in $[\mathbf{1 a}]^{+\cdot}$ and $[\mathbf{2 a}]^{+\cdot}$ after a lifetime of a few microseconds and that the ratio for the loss of $\mathrm{H}^{*}$ and $\mathrm{D}^{*}$ from metastable $[\mathbf{1 a}]^{+\cdot}$ and $[2 \mathrm{a}]^{+\cdot}$ is determined by an isotope effect $k_{\mathrm{H}} / k_{\mathrm{D}}=1.67-2.16$. This isotope effect depends on the internal energy of the fragmenting ions and approaches unity for ions energized by $\mathrm{CA}$.

The behaviour of the 2,5-dideutero- $4 \mathrm{H}$-pyran ions [3a] ${ }^{+*}$ with respect to losses of $\mathrm{H}^{*}$ and $\mathrm{D}^{*}$ is quite different from [1a $]^{+\cdot}$ and $[2 \mathrm{a}]^{+\cdot}$. The ratio for loss of $\mathrm{H}^{*}$ and $\mathrm{D}^{\cdot}$, respectively, from metastable [3a] ${ }^{+\cdot}$ is approximately $10: 1$, which is far from the statistical value of $2: 1$. Furthermore, the same ratio is observed for the collisionally induced dissociation (CID) of [3a] ${ }^{+\cdot}$ (Table 4). Unfortunately, we did not succeed in the synthesis of 4-deutero-4H-pyran, which should give a 1:1 ratio for specific loss of $\mathrm{H}^{\cdot}$ and $\mathrm{D}^{\circ}$, respectively, from position 4 in its mass-analysed ion kinetic energy (MIKE) spectrum in the absence of an isotope effect. In the case of [3a $]^{+\cdot}$, it is not possible to exclude rigorously an isotope effect as suggested by the independence of $H / D$ loss from the internal energy. Nevertheless, the results show that rather surprisingly no scrambling of $\mathrm{H}$ and $\mathrm{D}$ atoms occurs in $[3 a]^{+*}$ prior to its decomposition, in contrast to the methylfuran ions $[\mathbf{1 a}]^{+\cdot}$ and $[\mathbf{2 a}]^{+\cdot}$, but that mainly pyrylium ions $b$ are formed by specific and direct cleavage of a $\mathrm{C}-\mathrm{H}$ bond at position 4 of $[3 \mathrm{a}]^{+\cdot}$. In spite of this, the peaks for loss of $\mathrm{H}^{\circ}$ and $\mathrm{D}^{\circ}$ are flat-topped in the MIKE spectrum of $[3 \mathrm{a}]^{+*}$, and the values of $T_{50}=22.8 \mathrm{~kJ} \mathrm{~mol}^{-1}$ and $23.9 \mathrm{~kJ} \mathrm{~mol}^{-1}$, respectively, are only slightly smaller than for the loss of $\mathrm{H}^{*}$ from $[3]^{+\cdot}$.

\section{Appearance energies and thermochemistry}

The ionization energies (IE) of 1-3 and the appearance energies $(\mathrm{AE})$ of the $\left[\mathrm{C}_{5} \mathrm{H}_{5} \mathrm{O}\right]^{+}$ions and related fragment ions have been measured by the semilog-plot method ${ }^{9}$ and the results are given in Table 5.

Additional information about the thermochemistry and the reaction profile of the mass spectrometric reactions of 1-4 has been obtained by a MNDO calculation ${ }^{10}$ of the heats of formation $\left(\Delta H_{f}\right)$ of 1-4 and their molecular ions, and of the intermediates and products of the reactions. The MNDO geometries and $\Delta H_{\mathrm{f}}$ values are shown in Scheme 2 .

Our value of the IE of $\mathbf{1}$ is in reasonable agreement with that reported in the literature. ${ }^{11}$ Furthermore, the experimental IE values of $1,2,3$ and 6 are reproduced by the difference $\left[\Delta H_{\mathrm{f}}(\right.$ ion $)$ $\Delta H_{\mathrm{f}}($ molecule $\left.)\right]$ calculated by MNDO. MNDO is known to produce large systematic errors in the 
Table 5. Ionization energies and appearance energies of 1, 2, 3 and 6 (in $\mathrm{kJ} \mathrm{mol}^{-1}$ )

\begin{tabular}{|c|c|c|c|c|}
\hline \multirow{3}{*}{1} & & $\mathrm{IE}\left([\mathrm{M}]^{+}\right)$ & $A E\left([M-H]^{+}\right)$ & $\mathrm{AE}\left(\left[\mathrm{M}-\mathrm{CH}_{3}\right]^{+}\right)$ \\
\hline & Exp. & 827 & 1028 & \\
\hline & Calc. ${ }^{a}$ & 825 & 982 & \\
\hline 2 & Exp. & 834 & 1028 & \\
\hline & Calc. $^{a}$ & 834 & 980 & \\
\hline 3 & Exp. & 811 & 956 & \\
\hline & Calc. $^{a}$ & 825 & 971 & \\
\hline 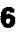 & Exp. & 821 & 953 & 853 \\
\hline & Calc. ${ }^{a}$ & 818 & 940 & 931 \\
\hline
\end{tabular}

a $A E($ calc. $)=\Delta H_{f}$ (ion) $+\Delta H_{f}$ (neutral fragment) $-\Delta H_{\mathrm{f}}$. (molecule); $\Delta H_{4}(\mathrm{H} \cdot)=218 \mathrm{~kJ} \mathrm{~mol}^{-1} ; \quad \Delta H_{4}\left(\mathrm{CH}_{3}{ }^{-}\right)=142 \mathrm{~kJ}$ $\mathrm{mol}^{-1} ; \quad \Delta H_{\mathrm{f}}(1)=-82 \mathrm{~kJ} \mathrm{~mol}^{-1} ; \Delta H_{\mathrm{f}}(2)=-80 \mathrm{~kJ} \mathrm{~mol}^{-1}$; $\Delta H_{f}(3)^{\prime}=-71 \mathrm{~kJ} \mathrm{~mol}^{-1} ; \quad \Delta H_{f}(6)=-81 \mathrm{~kJ} \mathrm{~mol}^{-1} ; \quad$ for $\Delta H_{f}($ ion) see Scheme 2.

energy values of ions and neutrals in some cases. ${ }^{12}$ Thus, the good agreement between experimental and calculated IE values indicates that MNDO reproduces well the relative $\Delta H_{\mathrm{f}}$ values of furans and furan ions, and pyran and pyran ions, respectively.

The calculated $\Delta H_{\mathrm{f}}$ values of the $\left[\mathrm{C}_{5} \mathrm{H}_{5} \mathrm{O}\right]^{+}$ions show that the pyrylium ion $b$ is the most stable species in this series, as expected (Scheme 2). The $\Delta H_{\mathrm{f}}$ of the isomeric furfuryl ions $a$ and $a^{\prime}$ are very similar and the $\Delta H_{\mathrm{f}}$ of the open-chained isomer $c$ falls into the same range of values. Hence, the MNDO order of stability of ions $a, a^{\prime}$ and $c$ may not be the real one, but the difference of $84-93 \mathrm{~kJ} \mathrm{~mol}^{-1}$ for $\Delta H_{\mathrm{f}}$ of $b$ is too large to be an artefact of the MNDO method. In fact, the $\mathrm{AE}$ of $\left[\mathrm{C}_{5} \mathrm{H}_{5} \mathrm{O}\right]^{+}$from the pyrans 3 and 6 (Table 5) indicate that MNDO probably underestimates the stability of the pyrylium ion $b$. The formation of pyrylium ions from $3,6^{*}$ and 7 by loss of $\mathrm{H}^{*}$ is associated with a large kinetic energy release (see Table 2) and, hence, with a reverse activation energy. Thus, the experimental $\mathrm{AE}$ values of these processes should be larger than the reaction enthalpies calculated from the $\Delta H_{\mathrm{f}}$ of products and precursors at least by the amount of $T_{50}$. This, however, is not observed and is only possible if $\Delta H_{\mathrm{f}}$ of $b$ calculated by MNDO is above the true value.

\section{DISCUSSION}

The formation of $\left[\mathrm{C}_{5} \mathrm{H}_{5} \mathrm{O}\right]^{+}$ions $(\mathrm{m} / z \mathrm{z1})$ is not only one of the main fragmentations in the EI mass spectra of alkylfurans and pyrans but also the predominant reaction of metastable molecular ions of 1-3, indicating that this is the energetically most favoured reaction. The formation of $\left[\mathrm{C}_{5} \mathrm{H}_{5} \mathrm{O}\right]^{+}$ions has also been observed in the EI mass spectra of hexa-2,4dienal and related compounds, ${ }^{13}$ and is again the most important fragmentation of metastable penta-2,4dienal ions $[4]^{+*}$. The structure of $b$ of pyrylium ions is usually assumed for these $\left[\mathrm{C}_{5} \mathrm{H}_{5} \mathrm{O}\right]^{+}$ions, and for the $\mathrm{m} / z 81$ ions investigated in this work the CA spectra (Table 3) are identical in most cases, proving identical structure(s) for the ions of different origin. In view of the special stability of the ion $b$, which is at least
$80 \mathrm{~kJ} \mathrm{~mol}^{-1}$ more stable than isomers $a, a^{\prime}$ and $c$ and the formation of these $\left[\mathrm{C}_{5} \mathrm{H}_{5} \mathrm{O}\right]^{+}$ions from pyran precursors 3,6 and 7 , it is only reasonable to assign to them structure $b$. An exception are the $m / z 81$ ions formed by EI from the 2-alkylfurans 1 and 5 . In these cases, the $\mathrm{CA}$ spectra of the $\left[\mathrm{C}_{5} \mathrm{H}_{5} \mathrm{O}\right]^{+}$ions show a small but distinct deviation in the intensity of the fragment ions at $\mathrm{m} / z$ 42. It has been shown that $\left[\mathrm{C}_{5} \mathrm{H}_{5} \mathrm{O}\right]^{+}$ions $a$ and $b$ do not interconvert. ${ }^{8}$ Therefore, we suggest that the increased intensity at $m / z 42$ in the CA spectra of $\left[\mathrm{C}_{5} \mathrm{H}_{5} \mathrm{O}\right]^{+}$ions derived from 1 and 5 is due to an admixture of a small amount of ions $a$, which are formed by high energy processes in the ion source.

Formation of the pyrylium ion $b$ from the molecular ions of the alkylfurans 1,2 and 5 requires a rearrangement, thus paralleling the isomerization reactions of alkylbenzene ions and their fragmentation to tropylium ions. However, whereas the molecular ions of alkylbenzenes and of the isomeric alkylcycloheptatriens equilibrate before fragmentation, as well as the resulting benzyl ions and tropylium ions, ${ }^{1,2}$ the mutual interconversion of furfuryl ions $a$ and pyrylium ions $b$ is not observed, and the complete isomerization of the molecular ions of isomeric alkylfurans and alkylpyrans can be excluded even after a lifetime of several microseconds by the different CA spectra of 1,2 and 3 , and 5,6 and 7 , respectively (Table 1). Thus, the reaction energy profile of the isomerization/ fragmentation process of methylfuran ions and $4 H$-pyran ions must be quite different from that of the corresponding process of toluene ions and cycloheptatriene ions, ${ }^{3}$ and the experimental results indicate the rearrangement of the molecular ions of methylfurans 1 and 2 and of pentadienal 4 into the isomeric pyran ions $[3]^{+\cdot},[8]^{+\cdot}$ or $[9]^{+\cdot}$ before loss of $\mathrm{H}^{\cdot}$, but not the reverse rearrangement $[3]^{+\cdot} \rightarrow[1]^{+\cdot}$ or $[2]^{+\cdot}$. This could be explained by an energy barrier for the isomerization step which is higher than that of the loss of $\mathrm{H}^{\cdot}$ from the pyran ions.

At first sight, the assumption of a reaction energy determining isomerization barrier seems to be corroborated by the observation of flat-topped peaks and large amounts of kinetic energy released during the loss of $\mathrm{H}^{\cdot}$ from the methylfuran ions $[1]^{+\cdot}$ and $[2]^{+*}$. This again indicates clearly a different kinetic behaviour of methylfuran ions from toluene ions losing a $\mathrm{H}$ atom without much kinetic energy release $^{4 a 5}$ (Table 2). However, a flat-topped peak and the same kinetic energy release are observed for the loss of $\mathrm{H}^{*}$ from $4 \mathrm{H}$-pyran ions $[3]^{+*}$. The origin of the released kinetic energy is therefore not the barrier of the isomerization step but an energy barrier of the last dissociation step. The rate determination by the dissociation step is also proven by the observation of an isotope effect during the $H / D$ loss from the molecular ions of $1 \mathbf{a}$ and $2 \mathbf{a}$. The origin of the energy barrier for the $\mathrm{H}^{*}$ loss by a formally simple bond cleavage in the $4 H$-pyran ions $[3]^{+*}$ is not clear. It arises probably from the different ground-state geometries of $[3]^{+\cdot}$ and $b$, as shown by the calculated bond lengths (Scheme 2). A 'simple' bond cleavage by elongation of the respective $\mathrm{C}-\mathrm{H}$ bond would give rise to a vibrationally excited product ion $b$. 

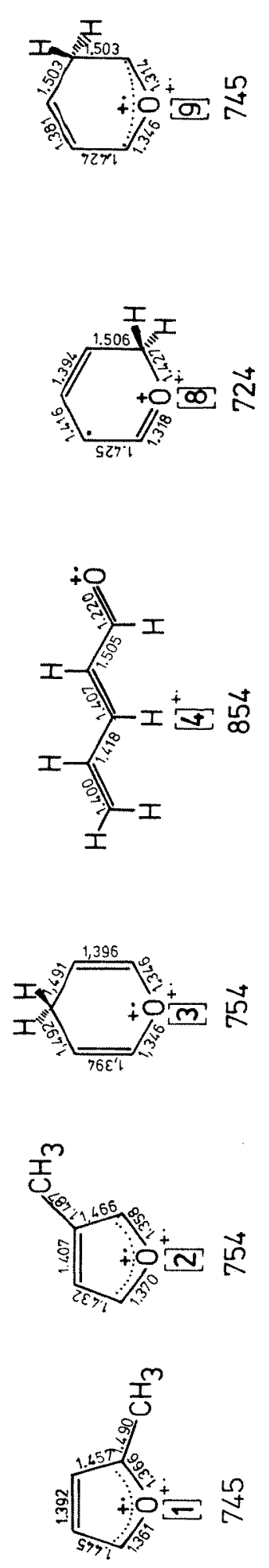
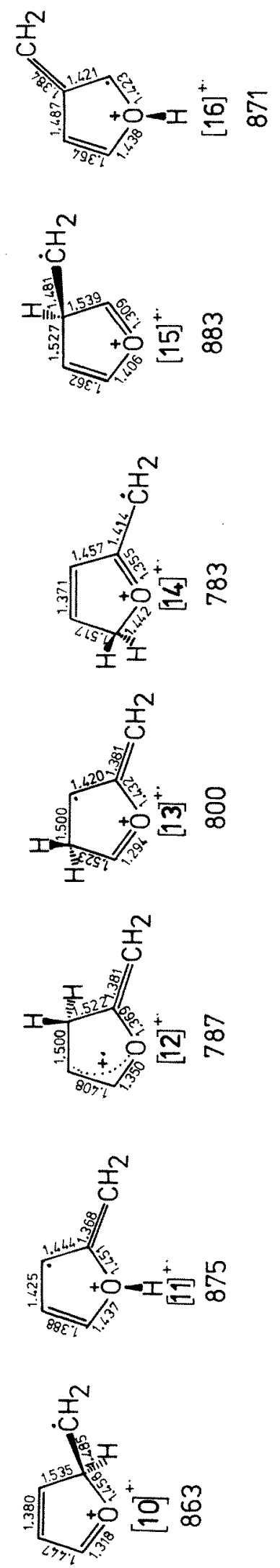
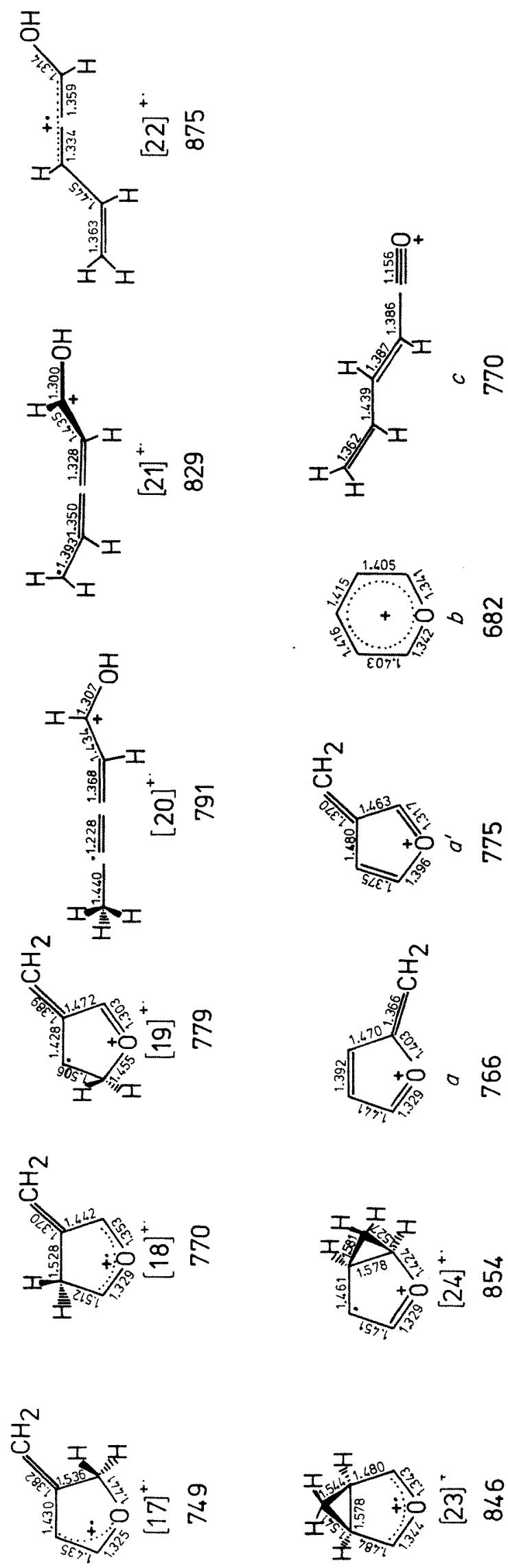
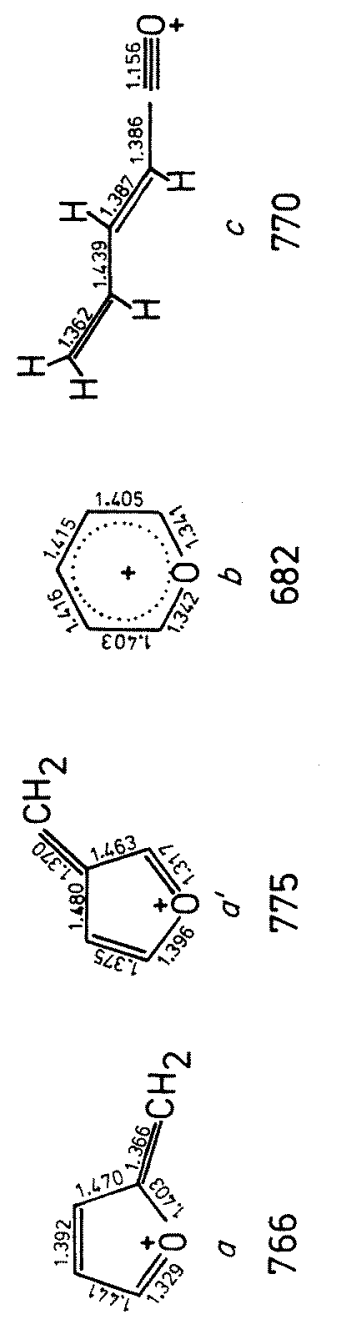

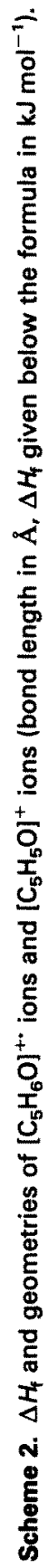

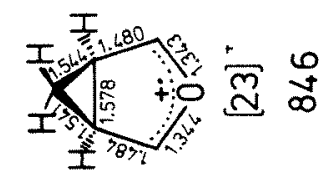


Obviously, a large amount of this excess energy of the transition state is released as kinetic energy. Interestingly, large kinetic energy releases are only observed for $\mathrm{H}^{*}$ losses from the molecular ions of 2-ethylfuran (5) and 3-methyl-4H-pyran (7) and not for the elimination of a $\mathrm{CH}_{3}{ }^{+}$radical from $[5]^{+\cdot},[6]^{+*}$ and $\left[7^{+*}\right.$, respectively, although the latter process also corresponds to the formation of the pyrylium ion $b$. The small values of $T_{50}$ and the Gaussian-shaped signals for the $\mathrm{CH}_{3}{ }^{*}$ elimination suggest a strong influence of rotational degrees of freedom in the transition state on the kinetic energy release.

Isomerization reactions preceding the fragmentations are also indicated by the study of deuterated methylfurans $1 \mathbf{a}$ and $\mathbf{2 a}$, showing complete $\mathrm{H} / \mathrm{D}$ scrambling within the molecular ions. In contrast to this, only a small amount of positional $H / D$ interchange is observed in the molecular ions of 2,5-dideutero-4H-pyran (3a) (Table 4). This structural stability of the $4 \mathrm{H}$-pyran ions is further corroborated by the rather specific loss of $\mathrm{CH}_{3}{ }^{\circ}$ and $\mathrm{H}^{*}$, respectively, from the molecular ions of 4-methyl- and 3-methyl-4H-pyran (6 and 7), even in their CA spectra (Table 1). A fast $\mathrm{H}$ migration in $[6]^{+\cdot}$ and $[7]^{+\cdot}$ should give rise to an identical mixture of ions prior to fragmentation. The absence of $H$ migrations in the $4 H$-pyran ions is rather surprising. MNDO calculations show (Scheme 2) that the $3 H$-pyran ion $[9]^{+\cdot}$ has a heat of formation between the $4 H$-pyran ion $[3]^{+\cdot}$ and the $2 \mathrm{H}$-pyran ion $[8]^{+*}$. $[9]^{+\cdot}$ would be an intermediate in isomerizations by $1,2-\mathrm{H}$ shifts, and its stability shows that the $\mathrm{H}$ migrations are prohibited by a critical energy of the $1,2-\mathrm{H}$ shift, which is larger than the critical energy of the fragmentation.

Because of the structural stability of the pyran ions, the complete $\mathrm{H} / \mathrm{D}$ scrambling in $[\mathbf{1 a}]^{+\cdot}$ and $[2 \mathbf{a}]^{+\cdot}$ by $\mathrm{H} / \mathrm{D}$ migration occurs either in some excited states of chemically activated pyran ions that are formed by a skeletal rearrangement of $[1 \mathbf{a}]^{+\cdot}$ and $[2 \mathbf{a}]^{+\cdot}$ and which are not accessible by $\mathrm{EI}$ or $\mathrm{CA}$ of $[\mathbf{3 a}]^{+*}$, or, more likely, by a H,D migration at some intermediate stages of the skeletal rearrangement process. The heats of formation, calculated by MNDO, of the distonic ions $[10]^{+\cdot}-[14]^{+\cdot}$ derived from $[1]^{+\cdot}$ and of $[15]^{+\cdot}-[19]^{+\cdot}$ derived from $[2]^{+\bullet}$ are below the sum of the heats of formation of the dissociation products $\left(b+\mathrm{H}^{*}\right)$, so that $\mathrm{H}$ migrations via these distonic ions are feasible in the absence of large activation energies of the 1,2-H shifts. However, the heats of formation of the isomeric open-chained $\left[\mathrm{C}_{5} \mathrm{H}_{6} \mathrm{O}\right]^{+\cdot}$ ions $[4]^{+\cdot}$ and $[20]^{+\cdot}-[22]^{+\cdot}$ are of the same order or even below those of the cyclic distonic ions. Hence, H/D scrambling in the deuterated methylfuran ions $[1 \mathrm{a}]^{+}$ and $[2 \mathbf{a}]^{+\cdot}$ via ring opening/ring closing reactions before a rearrangement to pyran ions is also possible.

A minimum energy reaction path (MERP) for the rearrangement of methylfuran ions $[1]^{+\cdot}$ and $[2]^{+\cdot}$ into pyran ions $[3]^{+\cdot}$ and $[9]^{+*}$ is shown in Scheme 3 . This MERP has been calculated by MNDO, assuming intermediate structures in close analogy to the rearrangement of $\left[\mathrm{C}_{7} \mathrm{H}_{8}\right]^{+\cdot}$ ions $^{3}$ and $\left[\mathrm{C}_{8} \mathrm{H}_{12}\right]^{+\cdot}$ ions. ${ }^{4}$ There is some uncertainty about the correct calculation of the potential energy of transition states by $\mathrm{MNDO}$, especially for $\mathrm{H}$ migrations, ${ }^{14}$ and in the present case it is very likely that MNDO overestimates especially the heats of formation of the transition states leading to pyrylium ion $b$, at least by a similar amount as $\Delta H_{\mathrm{f}}$ of $b$. Nevertheless, the reaction model derived from the MNDO calculation shows that large energy barriers separate the methylfuran ions $[1]^{+\cdot}$ and $[2]^{+\cdot}$ from the distonic ions $[10]^{+}$and $[15]^{+\cdot}$ at the starting point of the MERP, but these barriers are still below the activation energies for a dissociation into furfuryl ions $a$ and $a^{\prime}$. However, the activation energy for the dissociation of the pyran ions $[3]^{+*}$ and $[9]^{+\cdot}$ into the pyrylium ions $b$ is of the same height or even below these barriers. Hence, the entropically disfavoured isomerization of
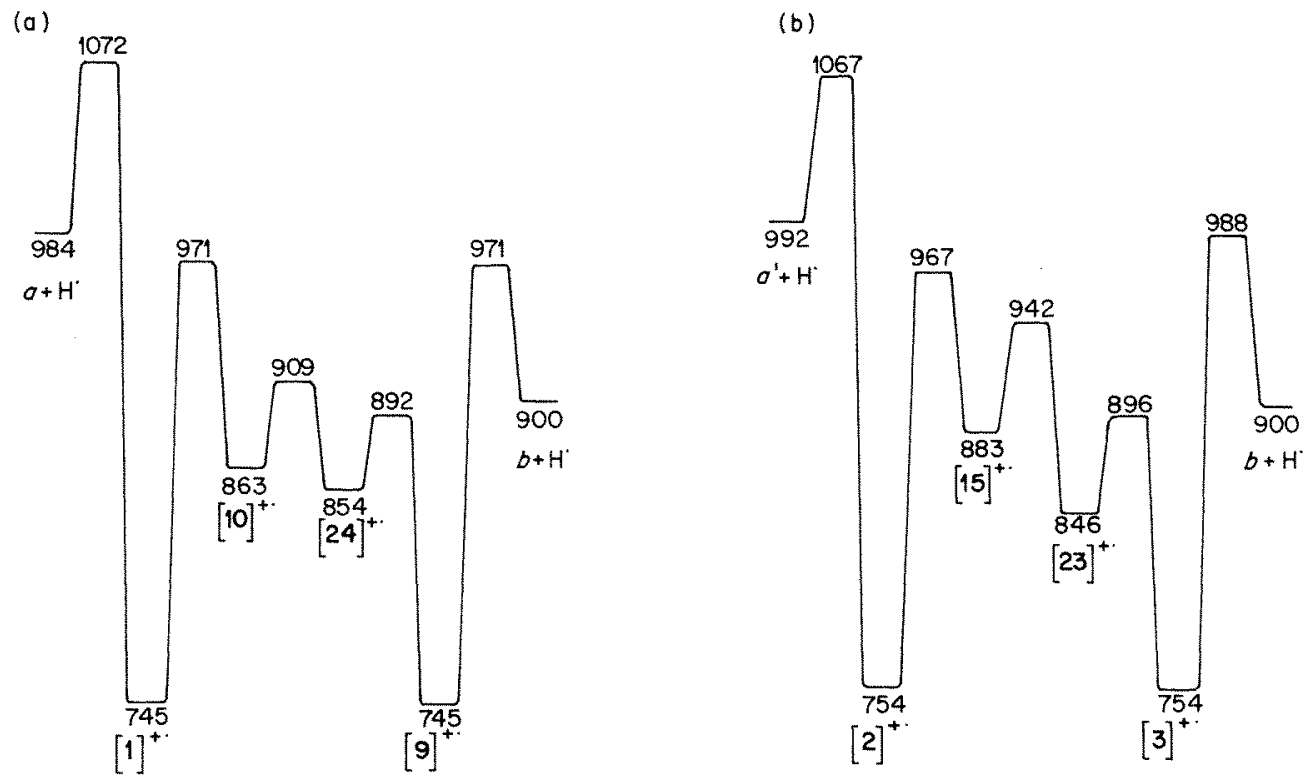

Scheme 3. MERP for the isomerization and fragmentation of $[1]^{+*}$ (a) and $[2]^{+*}$ (b) $\left(\Delta H_{j}\right.$ of ions and transition states in $\mathrm{kJ} \mathrm{mol}^{-1} ;$ for structures see Scheme 2). 
the pyran ions into $[1]^{+\cdot}$ and $[2]^{+\cdot}$ cannot compete with the dissociation process.

\section{EXPERIMENTAL}

The 70-eV EI mass spectra were measured with a MAT 311A mass spectrometer and the following experimental conditions: electron energy $70 \mathrm{eV}$, emitter current $3 \mathrm{~mA}$, acceleration voltage $3 \mathrm{kV}$, ion source temperature $180^{\circ} \mathrm{C}$.

The MIKE and CA measurements were performed with a double-focusing mass spectrometer VG ZAB2F equipped with a combined $\mathrm{EI} / \mathrm{CI}$ ion source using the following experimental conditions: electron energy $70 \mathrm{eV}$, electron trap current $50 \mu \mathrm{A}$, acceleration voltage $6 \mathrm{kV}$, ion source temperature $200^{\circ} \mathrm{C}$.

The reactions of metastable ions in the 2nd FFR of the VG ZAB-2F instrument were studied by focusing the relevant ion into the 2nd FFR and by varying the electrostatic field. CA/MIKE spectra were obtained by introducing $\mathrm{He}$ into the collision chamber of the 2nd FFR until the intensity of the main beam was reduced to $30 \%$.

The ionization energies and appearance energies were obtained with a modified VGMM 12B mass spectrometer using the semilog-plot method and $\mathrm{CH}_{3} \mathrm{I}$ $(\mathrm{IE}=9.5 \mathrm{eV})$ as a reference introduced with the sample. Operation conditions: trap current $20 \mu \mathrm{A}$, acceleration voltage $4 \mathrm{kV}$, ion source temperature $200^{\circ} \mathrm{C}$. The instrument is equipped with a device allowing preselection of up to eight peaks in a mass spectrum. The peaks are adjusted by the magnetic field and are measured by a cyclic scan. The mass spectrometer is coupled with a PDP-11 computer and the measurements are performed automatically in $10-\mathrm{meV}$ steps with an acquisition time of $40 \mathrm{~ms}$ per step. These devices allow the measurment of the ion intensities of interest under identical conditions in $<0.1 \mathrm{~s}$ for one run. The ionization and appearance energies are derived from these measurements by an evaluation of the semilogarithmic plot assisted by the PDP-11 computer. $\dagger$

\section{Compounds}

2-Methylfuran (1) and 2-ethylfuran (5) are commercially available from Aldrich Chemical Corp. 3-

$\uparrow$ The corresponding programs for the measurement and evaluation were developed by Dr U. Neuert, Fakultät Chemie, Universität Bielefeld, FRG.
Methylfuran (2) is prepared in analogy to the synthesis of 3,4-dimethylfuran described by Rawson. ${ }^{15}$ The 3-carboethoxyfuran is obtained by decarboxylation $^{16}$ of furan-3,4-dicarboxylic acid, followed by esterification with ethanol. $4 H$-pyran (3) is prepared as described by cyclization of the glutaraldehyde in dry $\mathrm{CH}_{2} \mathrm{Cl}_{2}$ at low temperature. ${ }^{17}$ Pentadienal (4) is prepared as described by Crombie. ${ }^{18}$ 3-Methyl- and 4-methyl-4H-pyran (6 and 7) are prepared in analogy to 3 by cyclization of $\alpha$ and $\beta$-methylglutaraldehyde, which are obtained by hydrolysing 3,4-dihydro-2-ethoxy-3-methyl- $2 \mathrm{H}$-pyran and 3,4-dihydro-2-ethoxy-4-methyl- $2 \mathrm{H}$-pyran. ${ }^{19} 2$ Trideuteromethylfuran (19) is obtained by reduction of furan-2-carboxylic acid with $\mathrm{LiAlD}_{4}$ in analogy to the preparation of 2. Furan-2-carboxylic acid is prepared by the oxidation of furfural with oxygen. ${ }^{20}$ 3-Trideuteromethylfuran (2a) is prepared as 2 but by using $\mathrm{LiAlD}_{4}$.

2,5-Dideutero- $4 \mathrm{H}$-pyran 3a. A mixture of $10 \mathrm{ml}$ of cyclopentanone, $10 \mathrm{ml}$ of $\mathrm{D}_{2} \mathrm{O}, 10 \mathrm{ml}$ of dry THF and $0.1 \mathrm{~g}$ of $\mathrm{K}_{2} \mathrm{CO}_{3}$ is stirred for $10 \mathrm{~h}$ at room temperature. Then, it is extracted with three $20-\mathrm{ml}$ portions of ether, the fractions are combined and the solvent is evaporated. This procedure is repeated three times and yields 2,2,5,5-tetradeuterocyclopentanone. The reduction of the deuterated cyclopentanone with $\mathrm{LiAlH}_{4}$ as described by Kloetzel and Pinkus ${ }^{21}$ yields 2,2,5,5-tetradeuterocyclopentanol. 1,3,3-Trideuterocyclopentene is distilled from a mixture of the tetradeuterated cyclopentanol and an equivalent amount of $85 \%$ phosphoric acid by heating to $120^{\circ} \mathrm{C}$. The oxidation of the cyclopentene with $\mathrm{H}_{2} \mathrm{O}_{2}$ yields 1,3,3-trideuterocyclopentane-1,2-diol. ${ }^{22} \mathrm{~A}$ further oxidation with $\mathrm{NaIO}_{4}$ in aqueous THF gives the corresponding deuterated glutaraldehyde, which is cyclized as described above to yield 2,5-dideutero- $4 H$-pyran (3a).

\section{Acknowledgements}

The financial support of this work by the Fonds der Chemischen Industrie and by the Deutsche Forschungsgemeinschaft is gratefully acknowledged. We also thank Dr U. Neuert, Fakultät Chemie, Universität Bielefeld, for development of the programs for measurement and evaluation of the semilogarithmic plots.

\section{REFERENCES}

1. (a) P. N. Rylander and S. Meyerson, J. Am. Chem. Soc. 78 , 5794 (1956); (b) P. N. Rylander and S. Meyerson, J. Am. Chem. Soc. 79, 842 (1957); (c) S. Meyerson and P. N. Rylander, J. Org. Chem. 62, 2 (1958); (d) M. A. Baldwin, F. W. McLafferty and D. M. Jerina, J. Am. Chem. Soc. 97. 6169 (1975); (e) F. W. McLafferty and F. M. Bockhoff, Org. Mass Spectrom. 14, 181 (1979); (f) D. Kuck and H. F. Grützmacher, Mass Spectrom. 14, 86 (1979).
2. For review see (a) K. Levsen, Fundamental Aspects of Organic Mass Spectrometry, Verlag Chemie, Weinheim (1978); (b) Mass Spectrometry, Specialist Periodical Reports, Vols 1-6, The Chemical Society, London (1971, $1973,1975,1977,1979$ and 1981).

3. M. J. S. Dewar and D. Landman, J. Am. Chem. Soc. 99, 2446 (1977).

4. (a) J. Grotemeyer and H. F. Grützmacher, in Current Topics 
in Mass Spectrometry and Chemical Kinetics, ed. by $\mathbf{A}$ Maccoll, Heyden, London (1982); (b) J. Grotemeyer and H. F. Grützmacher, Org. Mass Spectrom. 17, 359 (1982).

5. B. J. Stapleton, R. D. Bowen and D. H. Williams, J. Chem. Soc., Perkin Trans. 2, 1219 (1979).

6. (a) Q. N. Porter and J. Baldas, Mass Spectrometry of Heterocyclic Compounds, Wiley, New York (1971). (b) K. Heyns, R. Stute and H. Scharmann, Tetrahedron 22, 2223 (1966).

7. H. F. Grützmacher and R. Spilker, Org. Mass Spectrom. 20, 258 (1985).

8. H. E. Audier, Y. Hoppilliard and D. Robin, 10th Int. Mass Spectrom. Conf. Swansea, UK, 9-13 September (1985).

9. F. P. Lossing, A. W. Tickner and W. A. Bryce, J. Chem. Phys. 19, 1254 (1981).

10. M. J. S. Dewar and W. Thiel, J. Am. Chem. Soc. 99, 4899 (1977).

11. H. M. Rosenstock, K. Draxel, B. W. Steiner and J. T. Herron, J. Phys. Chem. Ref. Data 6, suppl. (1977).

12. see Y. Apeloig, M. Karni, B. Ciommer, G. Depke, G. Frenking, S. Meyn, J. Schmidt and H. Schwarz, Int. J. Mass Spectrom. Ion Phys. 59, 21 (1984).
13. (a) H. Schwarz, B. Richter and F. Bohlmann, Org. Mass Spectrom. 10, 1125 (1975); (b) for related reactions, see J. Grotemeyer and H. F. Grützmacher, Int. J. Mass Spectrom. lon Phys. 47, 399 (1983).

14. M. J. S. Dewar and K. M. Merz Jr, J. Am. Chem. Soc. 107, $6111(1985)$.

15. D. I. Rawson, B. K. Carpenter and H. M. R. Hoffmann, J. Am. Chem. Soc. 101, 1786 (1979).

16. T. Reichstein, A. Grüssner, K. Schindler and E. Hardmeier, Helv. Chim. Acta 16, 276 (1933).

17. J. Strating, Houben-Weyl, Bd. VI/4, 109 Thieme Verlag (1966).

18. L. Crombie, S. H. Harper and D. Thompson, J. Chem. Soc. 2906 (1951).

19. R. I. Longley Jr and W. S. Emerson, Org. Synth. Coll. IV, 660 (1963).

20. R. J. Harrison and M. Moyle, Org. Synth. Coll. IV, 493 (1963).

21. M. C. Kloetzel and J. L. Pinkus, J. Am. Chem. Soc. 80, 2331 (1958).

22. L. N. Owen and P. N. Smith, J. Chem. Soc. 4030 (1952). 